\title{
UCRL-TR-205787
}

\section{CT Scan of NASA Booster Nozzle}

\author{
Daniel Schneberk
}

\section{July 2004}

This work was performed under the auspices of the U. S. Department of Energy by the University of California, Lawrence Livermore National Laboratory under Contract No. W-7405-Eng-48. 
This document was prepared as an account of work sponsored by an agency of the United States Government. Neither the United States Government nor the University of California nor any of their employees, makes any warranty, express or implied, or assumes any legal liability or responsibility for the accuracy, completeness, or usefulness of any information, apparatus, product, or process disclosed, or represents that its use would not infringe privately owned rights. Reference herein to any specific commercial product, process, or service by trade name, trademark, manufacturer, or otherwise, does not necessarily constitute or imply its endorsement, recommendation, or favoring by the United States Government or the University of California. The views and opinions of authors expressed herein do not necessarily state or reflect those of the United States Government or the University of California, and shall not be used for advertising or product endorsement purposes. 


\section{CT Scan of NASA Booster Nozzle}

\section{Introduction \& Scan Parameters}

At the request of Ron BeShears and Mike Suits we performed DR/CT scanning of NASA Booster Nozzle. The nozzle was cut in half. Figure 1 contains an image of the nozzle on the stage used to perform the scan. The scan was performed on out HECAT system, which includes a 9 meV VARIAN Linatron (w’ 1mm spot), a custom 3-panel collimator, a THALES 14-bit AmSi panel, and NEWPORT Air bearing table and motion control hardware (see Figure 2). Using this hardware and LLNL software we acquired three 600 view rotation-only scans to evaluate different filtering schemes. Best inspection was obtained with 0.125 inch Tantalum filter and the half-nozzle mounted as shown in Figure 1. For this scanner the source to detector distance is $5750 \mathrm{~mm}$, with the object positioned at $400 \mathrm{~mm}$ from the detector. With this geometry the cone angle is approximately 1.5 degrees. The scatter in the object was sufficient to warrant a global resample of 1.5 pixels, $0.1905 \mathrm{~mm}$ pixel size at the detector, which reconstructs into 0.1745 at the object. To reduce read-out noise each 6 frames were averaged for each radiographic view. The 600 radiographic views were processed and reconstructed into 3D CT data with LLNL software.

\section{DR \& CT Data}

Figure 3 contains a single digital radiographic image and Figure 4 contains the unsharp-mask transform of this particular view. A variety of features are visible in this particular view. Notice the indications of defects in the rubber outer coating of the nozzle. Further, notice the change in contrast in the thicker parts of the Aluminum. With $9 \mathrm{meV}$ LINAC spectrums the scatter generated through the long chords in the Aluminum degrade the contrastive performance of this imager.

Figure 5 contains a crossectional slice through the nozzle. Figure 6 contains a vertical slice through volume (in the Y-Direction), and Figure 7 contains a vertical slice through the volume perpendicular to the slice orientation in Figure 6. This inspection data shows numerous indications of voids in the outer rubber/carbon coating next to the Aluminum. Figure 8 contains a crossectional slice showing one on the small voids at the end of the nozzle. As shown in the figures these voids are on both sides of the nozzle and at the ends. The voids vary in extent from 1-2 $\mathrm{mm}$ to $20 \mathrm{~mm}$ on the major aspect of the void.

Figure 9-13 contains a number of vertical slices through the volume focusing on the adhesive layer between the Aluminum and the inner layer of carbon. For all of these slices there appears to be a slight variation in the thickness of this adhesive layer. For all the slices we saw no indications of voids in the adhesive layer greater than 3 pixels ( 21 mils for this data set). Three movies have been included with this report for viewing the slices in sequence through the volume.

We have developed a variety of tools for extracting layers and contours from closed contour objects. Using the sequence of slices in the X-direction we extracted a voxel average around the adhesive layer as it meets the Aluminum interface. This image is included in Figure 14. We are 
not exactly in the optimum angle for lifting out the data in the contour and some of the blur in the data is due to averaging from this direction in the volume. At present we are working on retuning our software to work better with hemi-spheres. These tools should enable us to extract the adhesive layer from the 3D volume, presenting that layer on that contour as a single image for viewing. We did not apply our dimensional measurement tools to these data. However that analysis could be performed subsequently.

\section{Summary}

We scanned a Booster Nozzle for NASA with our 9 meV LINAC, AmSi panel scanner. Three scans were performed using different filtering schemes and different positions of the nozzle. The results of the scan presented here are taken from the scan which provided the best contrast and lowest noise of the three. Our inspection data shows a number of indications of voids in the outer coating of rubber/carbon. The voids are mostly on the side of the nozzle, but a few small voids are present at the ends of the nozzle. We saw no large voids in the adhesive layer between the Aluminum and the inner layer of carbon. This 3D inspection data did show some variation in the size of the adhesive layer, but none of the indications were larger than 3 pixels in extent (21 mils).

We have developed a variety of contour estimation and extraction techniques for inspecting small spaces between layers. These tools might work directly on un-sectioned nozzles since the circular contours will fit with our tools a little better. Consequently, it would be useful to scan a full nozzle to ensure there are no untoward degradations in data quality, and to see if our tools would work to extract the adhesive layer. 


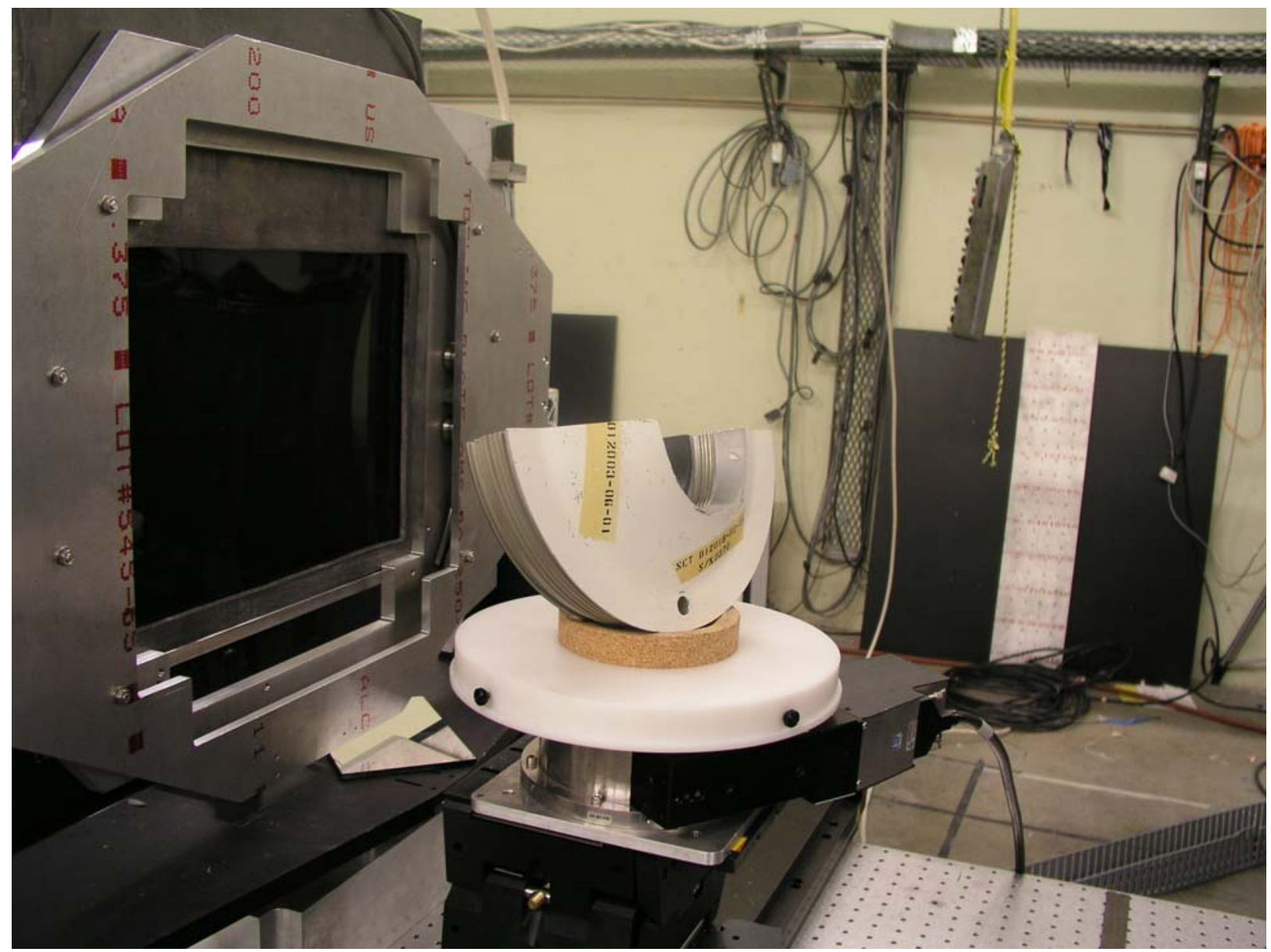

Figure 1 - Digital Image of Sectioned Nozzle on the rotational stage as scanned on HECAT at LLNL (THALES AmSi panel to the left) 

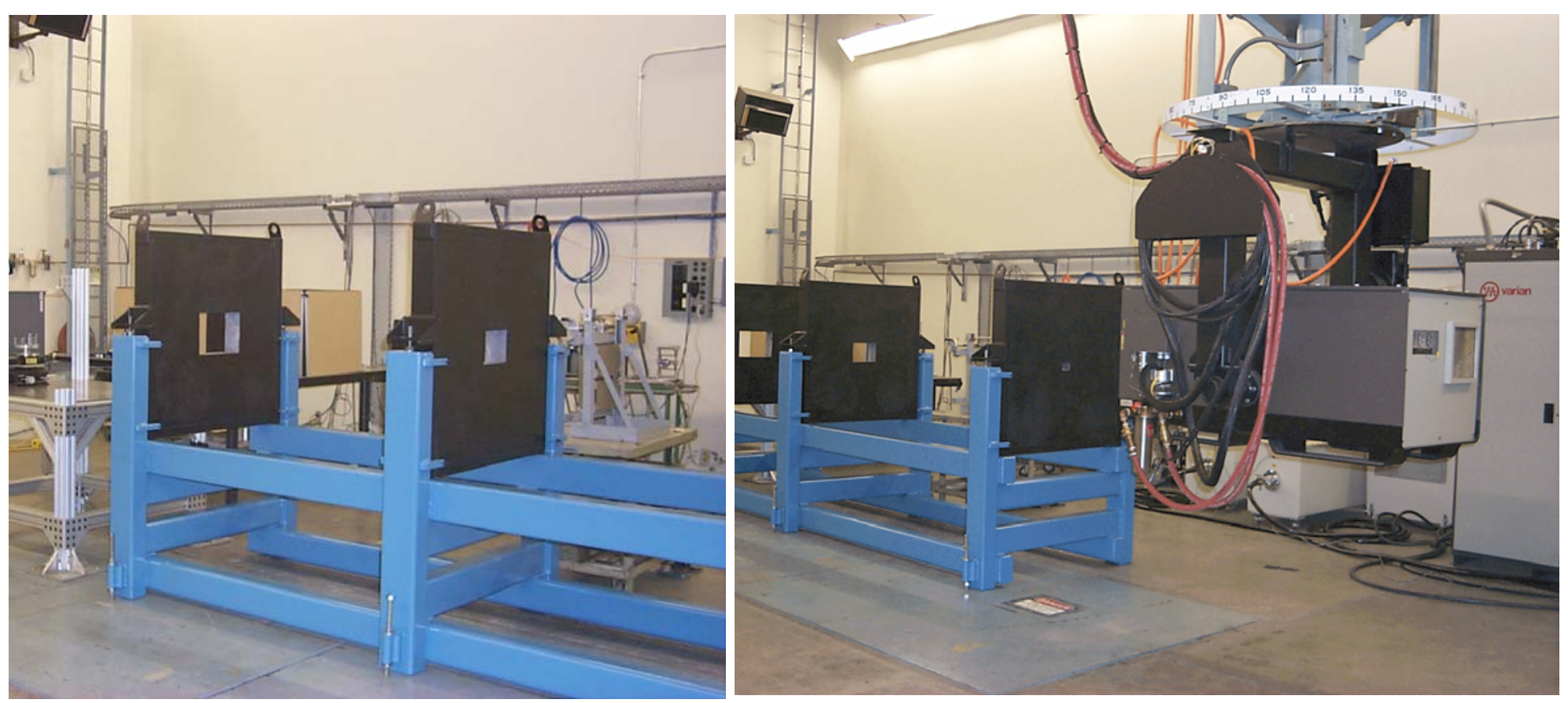

Figure 2 - Picture of HECAT components - Stonehenge II Collimator and VARIAN LINAC

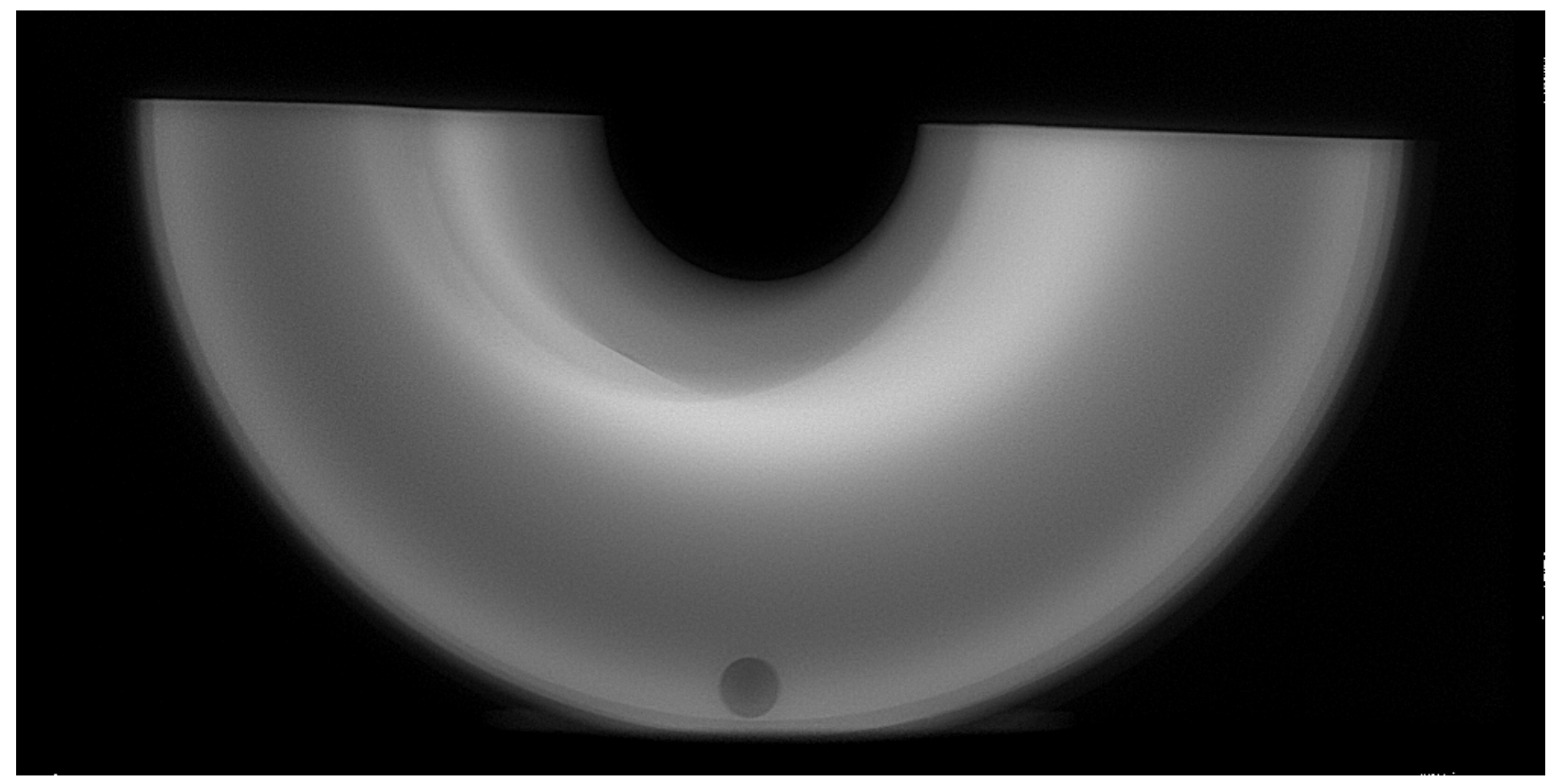

Figure 3 - Digital Radiograph of Sectioned NASA Nozzle from HECAT system 


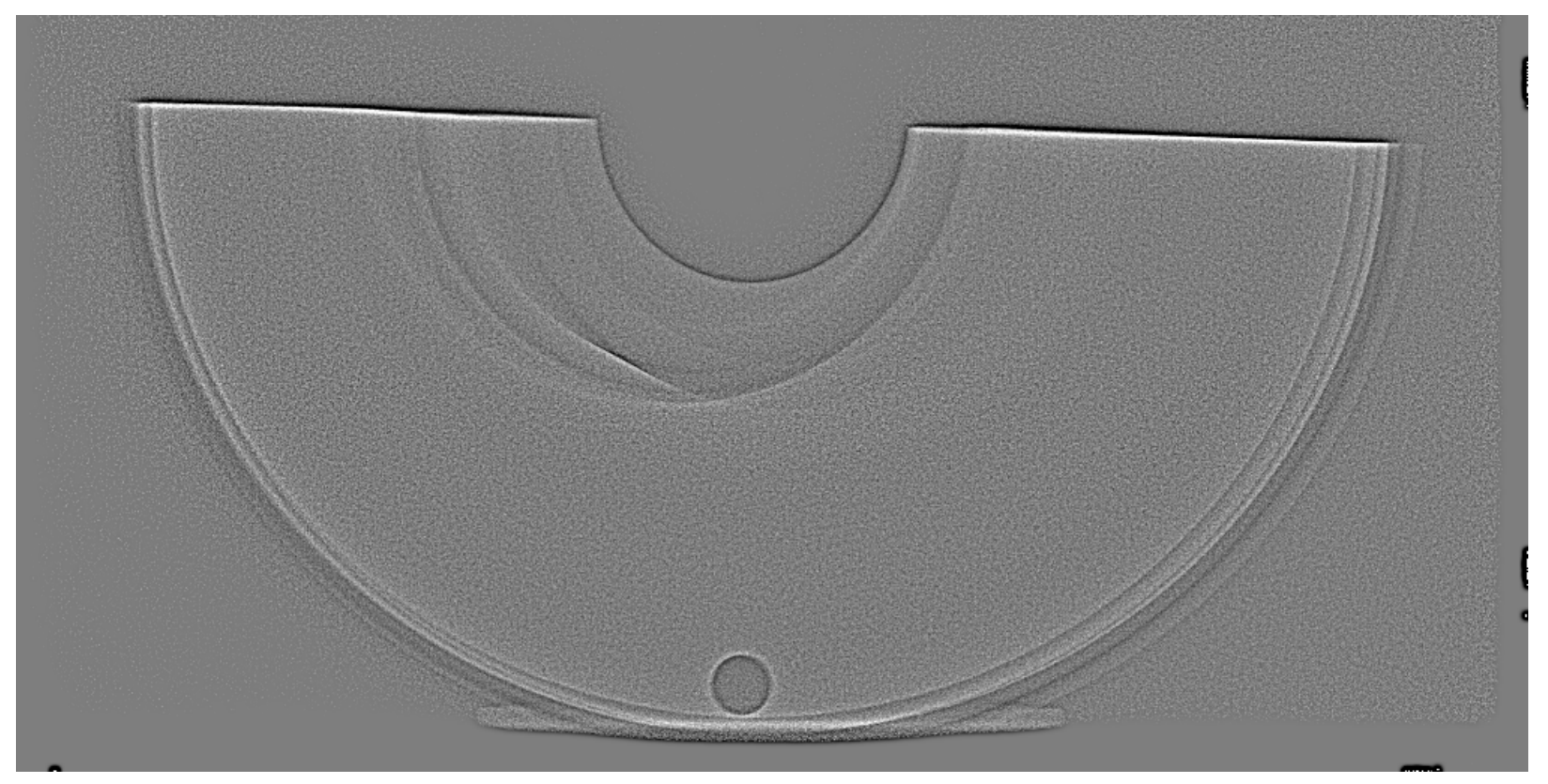

Figure 4 - Unsharp Mask Filtered Digital Radiograph of NASA Nozzle from HECAT system

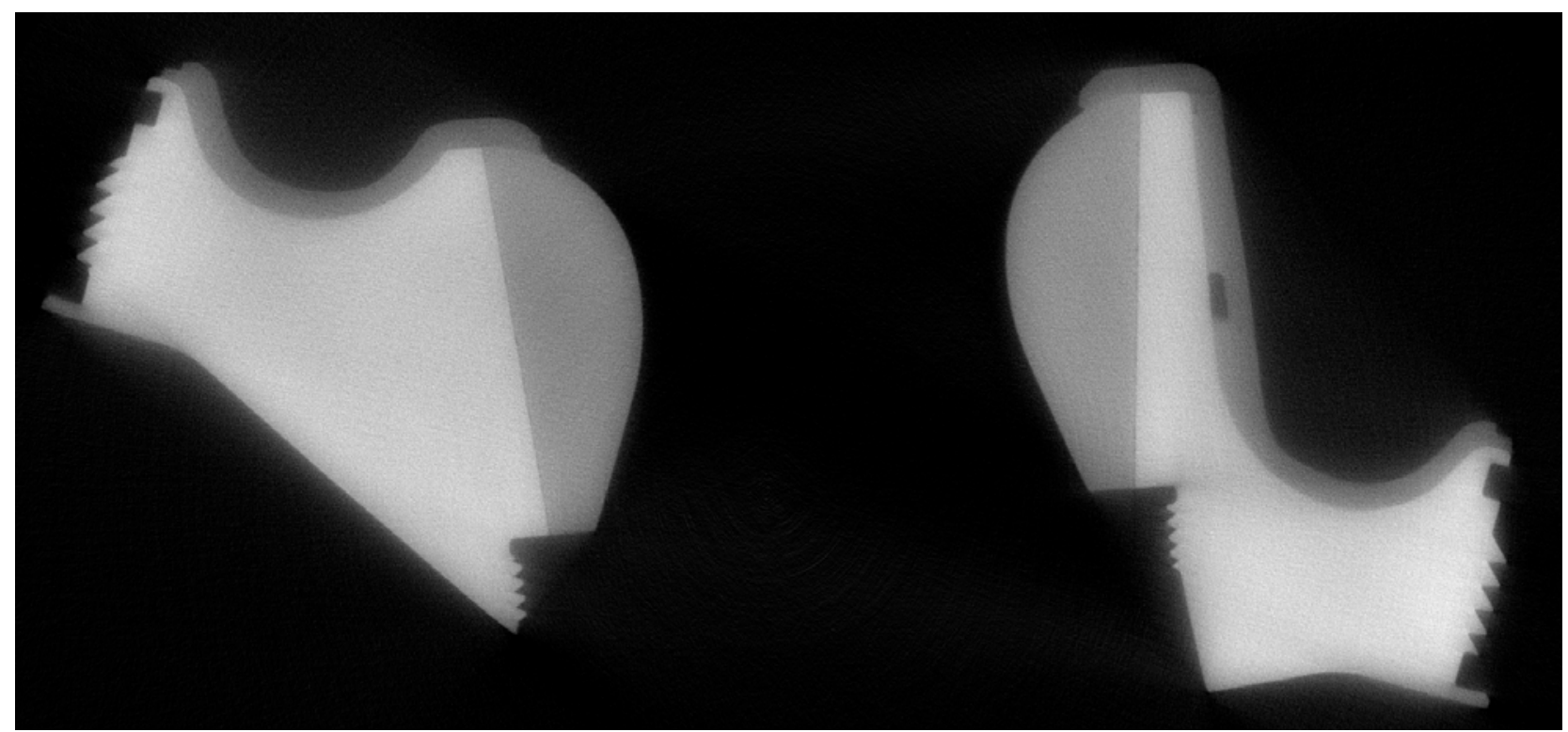

Figure 5 - Crossectional CT slice through NASA Sectioned Nozzle 
Figure 6 - Vertical CT slice through NASA Sectioned Nozzle - in the Y-Dimension

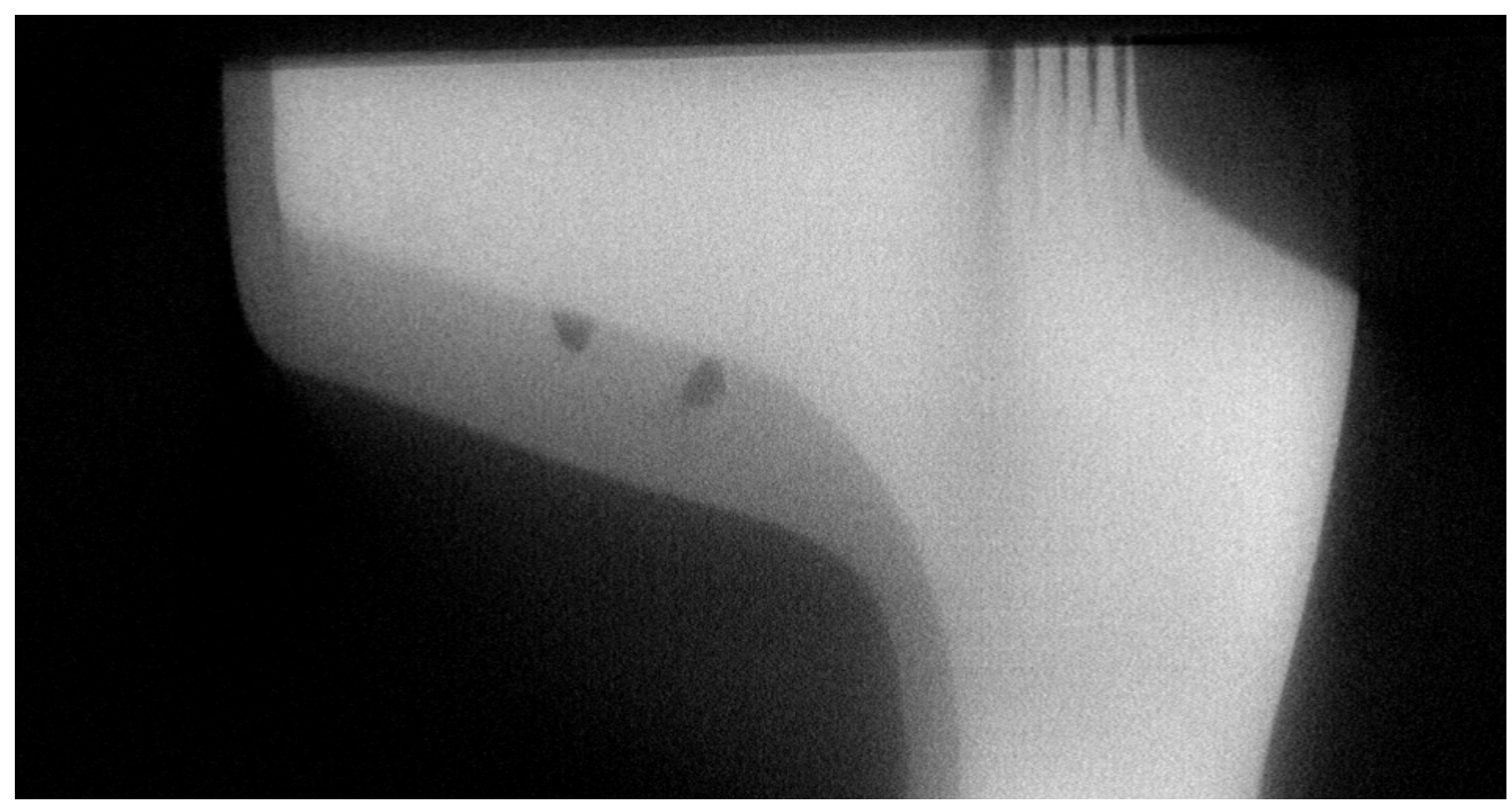

Figure 7 - Vertical slice through the NASA Nozzle - in the X-dimension 


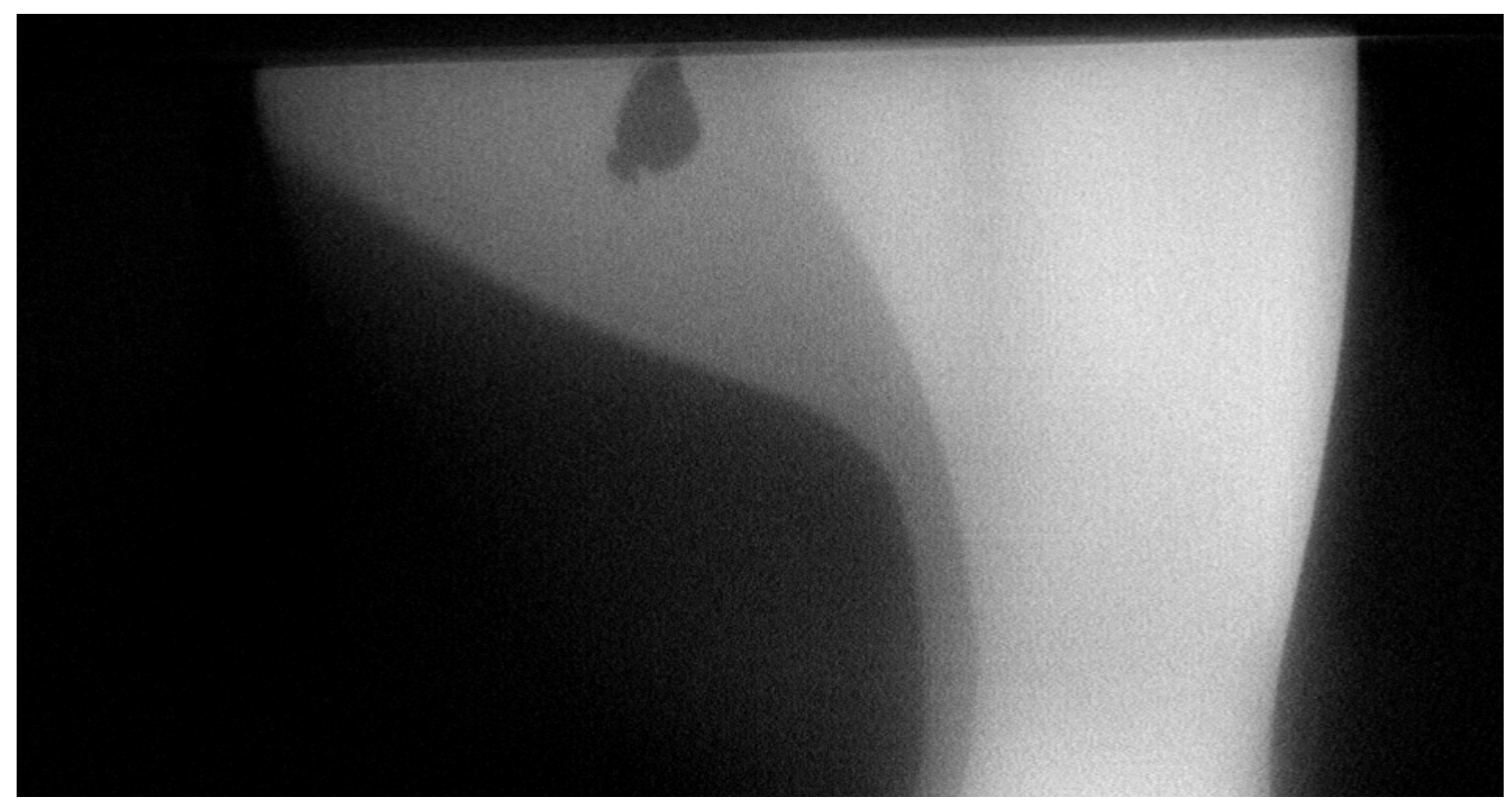

Figure 8 - Vertical Slice through NASA Sectioned Nozzle - in the X-Direction

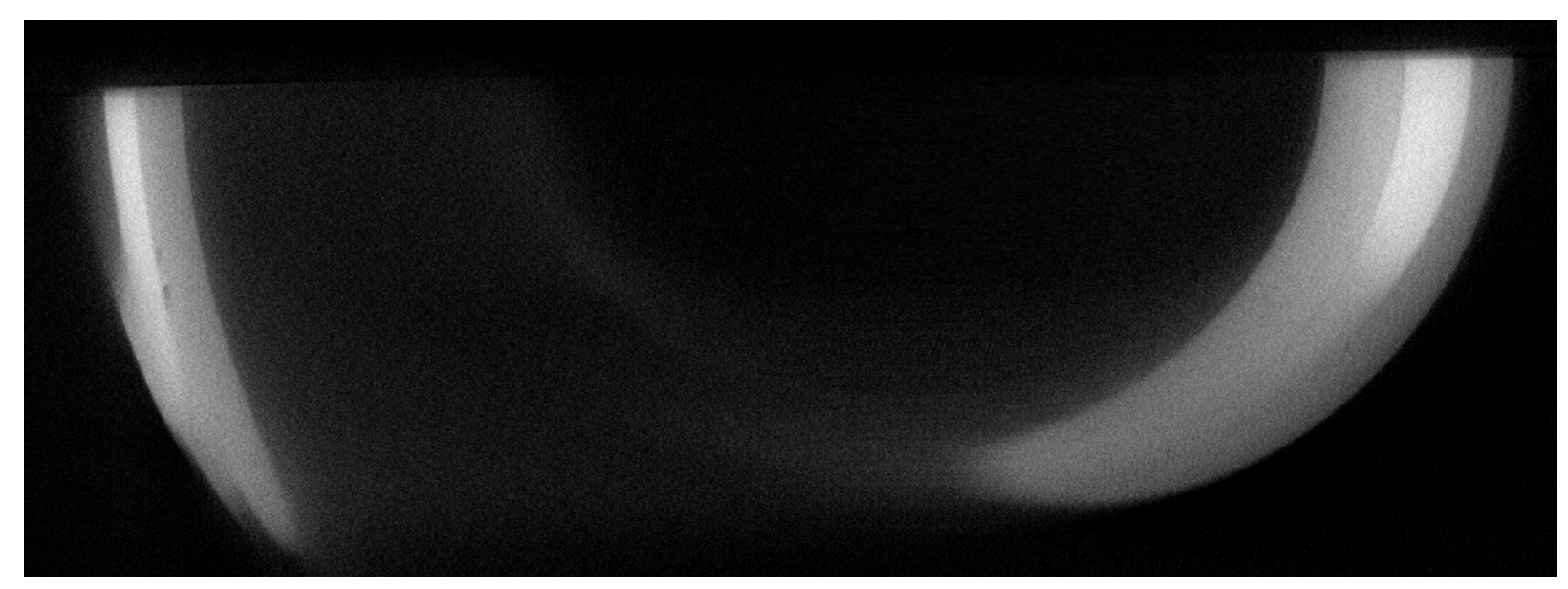

Figure 9 - First of successive Vertical slices in the Y-Direction 


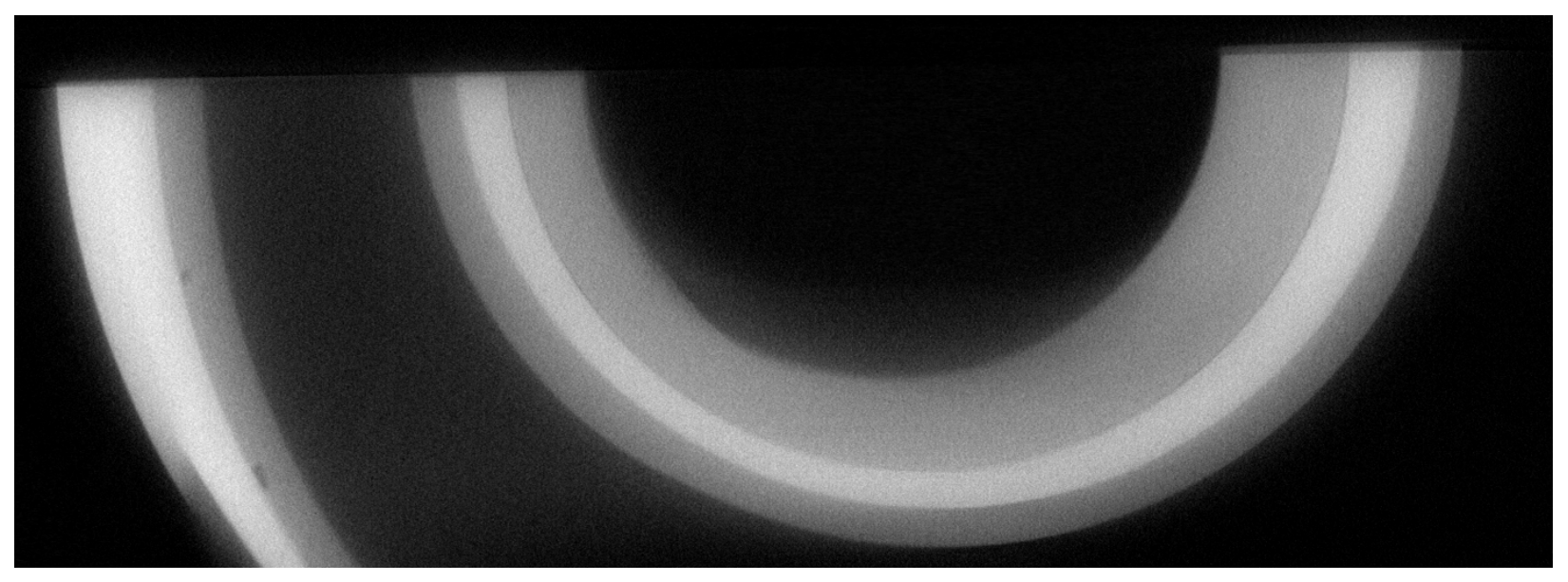

Figure 10 - Second of successive Vertical slices in the Y-Direction

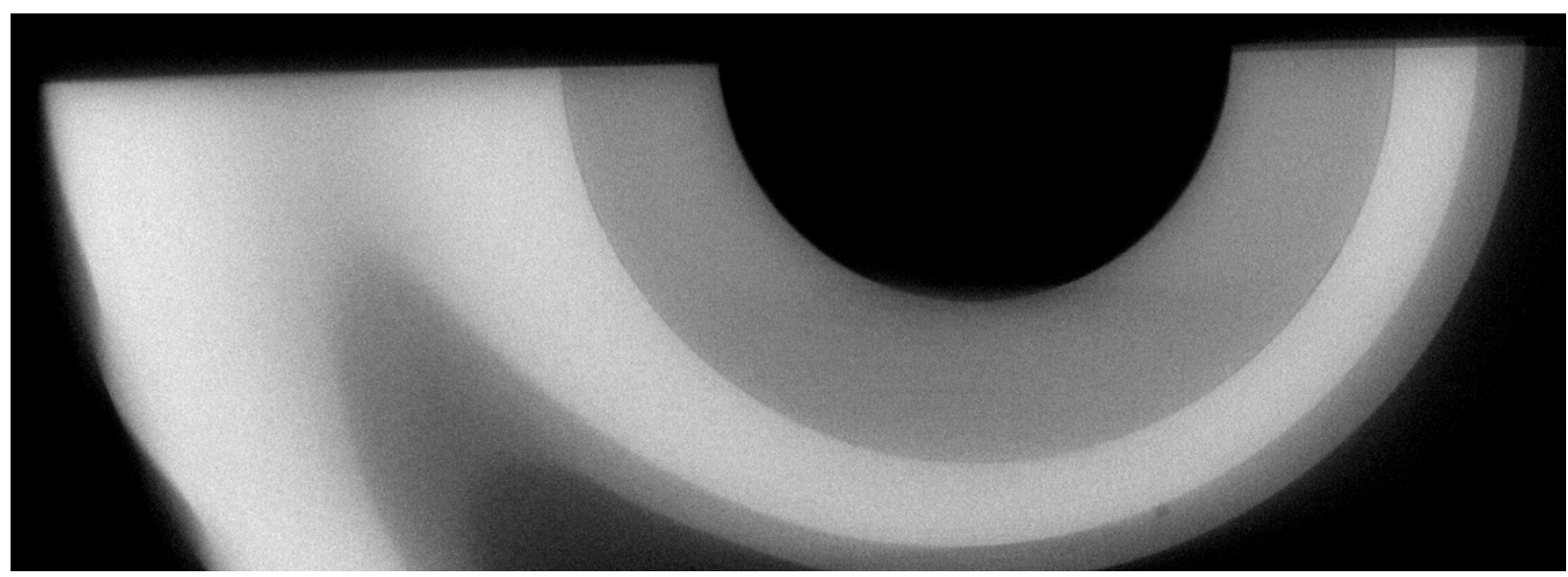

Figure 11 - Third of successive Vertical slices in the Y-Direction

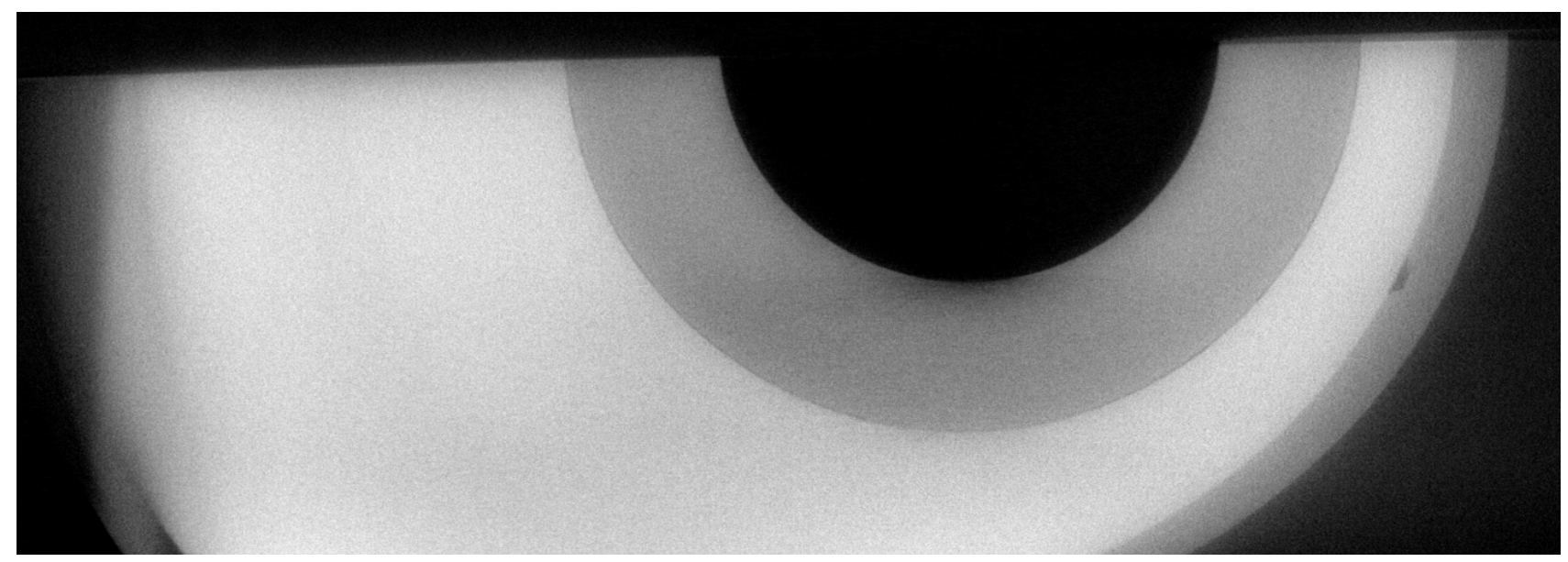

Figure 12 - Fourth of successive Vertical slices Y-Direction 


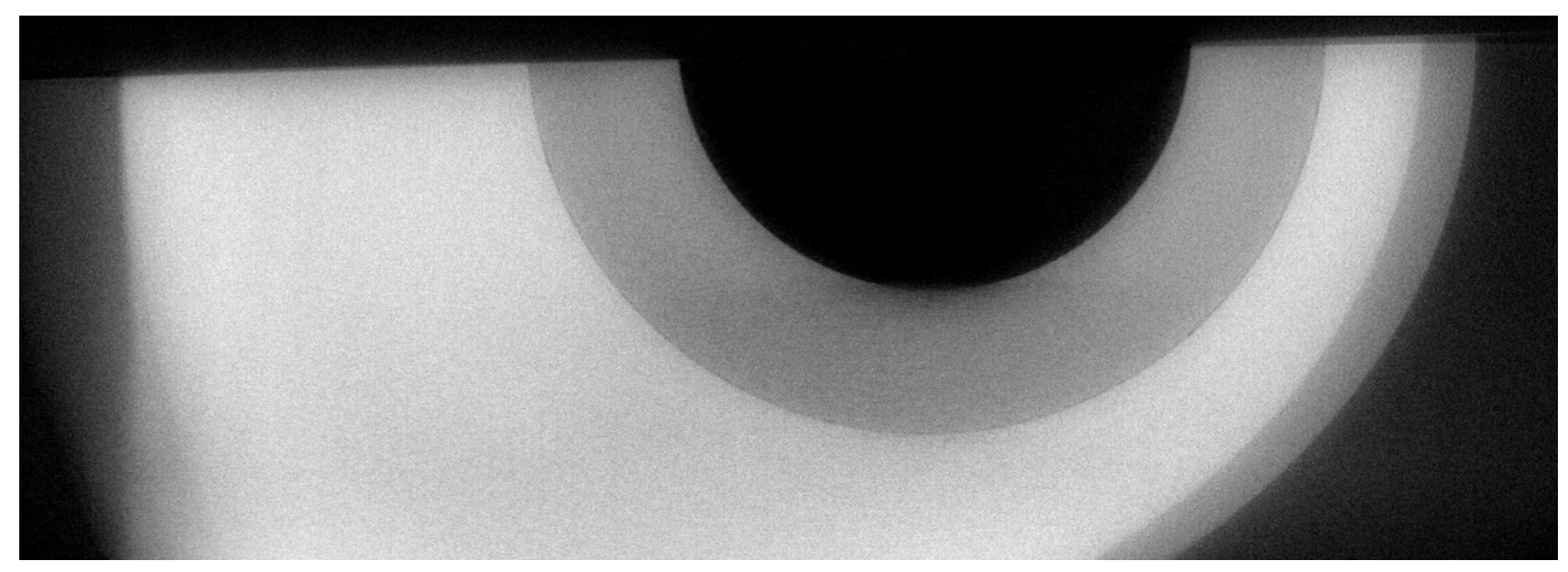

Figure 13 - Fifth successive Vertical slice in the Y-Direction 


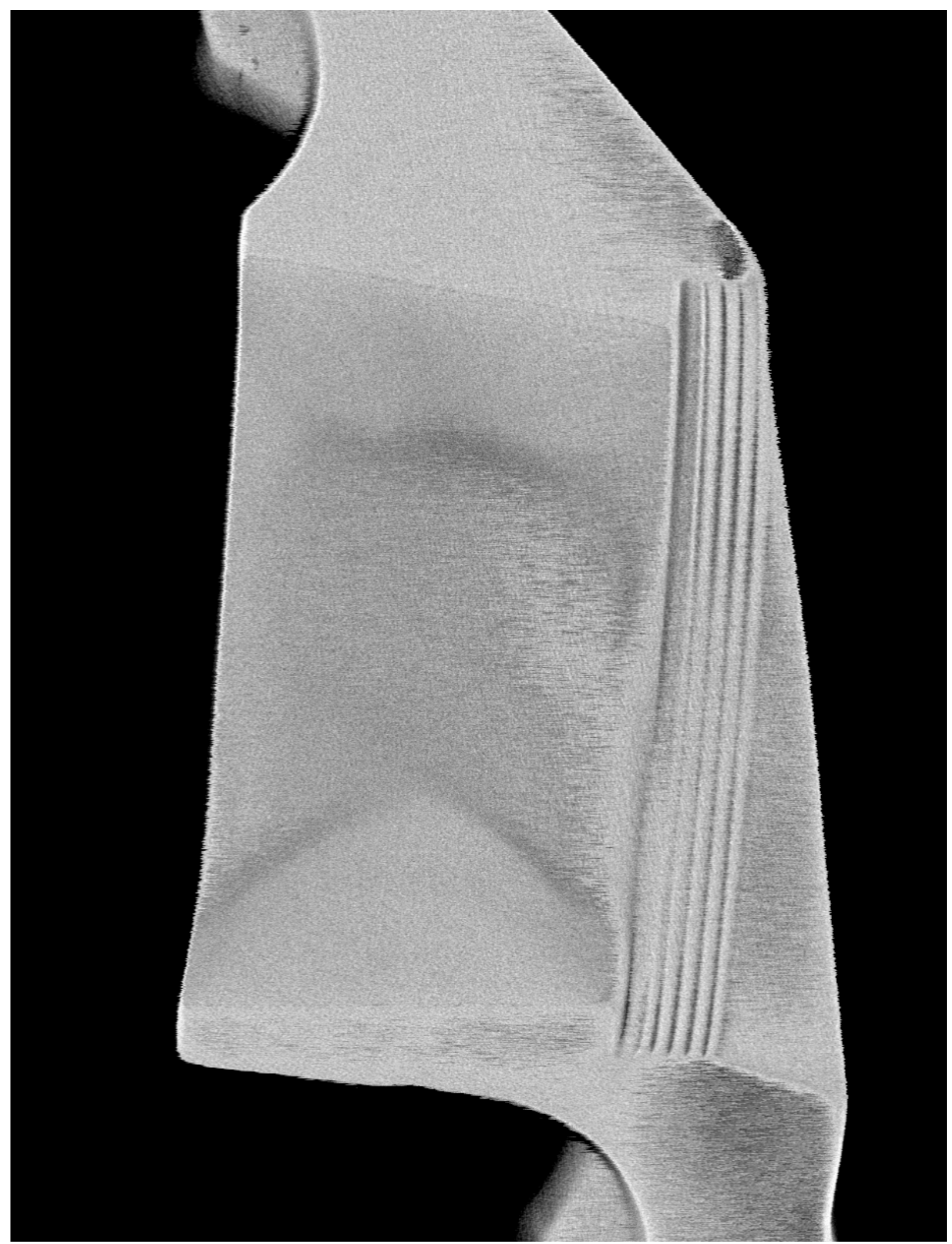

Figure 14 - Averaged voxel values in adhesive contour layer 